\title{
Comparison of Lurasidone and Olanzapine in Schizophrenia- A Open label study
}

Authors

\author{
Dr A.Vijaya Chandra Reddy M.D (Psychiatry) ${ }^{1}$, \\ Dr Kandavalli Sridevi M.D (Pharmacology) ${ }^{2}$ \\ ${ }^{1}$ Associate Professor of Psychiatry RIMS Kadapa \\ Mobile 94929860420, Email: Chandra.avula@gmail.com \\ ${ }^{2}$ Associate Professor of Pharmacology, RIMS Kadapa \\ Corresponding Author \\ Dr. Kandavalli Sridevi M.D (Pharmacology) \\ Mobile 73826226669, Email: drsridevi19@gmail.com
}

\begin{abstract}
The study was conducted at RIMS general Hospital Psychiatry OP and study evaluated comparative efficacy and safety Lurasidone in comparison to Olanzapine in first episode schizophrenia diagnosed based on ICD-10.126 first episode schizophrenia patients participated in the study out which 60 patients were in olanzapine group and 66 patients Lurasidone group. PANSS and CGI-I were used assess and compare efficacy. Lurasidone was non inferior to olanzapine in decreasing PANSS score from baseline to end of study at 12 $2^{\text {th }}$ week (95\% CI: -8.9 to 4.5). Lurasidone and Olanzapine were equally effective in treating the first episode schizophrenia.

Conclusion: In our study after analysis Lurasidone was equally efficacious in treating first episode of schizophrenia.
\end{abstract}

Keywords: Lurasidone, Olanzapine, first episode schizophrenia, response rates, PANSS, CGI-I.

Open Label comparative study of Lurasidone and Olanzapine treating first episode of Schizophrenia

Schizophrenia is a chronic psychiatric disorder effecting $1 \%$ of population ${ }^{1,2,3}$. The incidence of schizophrenia $0.1-0.4$ per 1000 in $10(\mathrm{WHO})^{2}$. The main stay of treatment for schizophrenia is antipsychotics and current the first choice is second generation antipsychotics ${ }^{4}$ and in them Olanzapine is the frequent choice of psychiatrists. Recently Lurasidone has been introduced in Indian market which has different receptor profile and hence a comparative study would establish any clinical relevance of unique receptor profile of Lurasidone. Lurasidone is $2^{\text {nd }}$ generation antipsychotic strongly binds D2, D3, D4, 5HT $(2 \mathrm{~A})$ and $5 \mathrm{HT}^{(7) .}$ Lurasidone showed preferential effect on ventral striatum prefrontal cortex. Based on receptor profile Lurasidone possess antipsychotic, antidepressant and anxiolytic effect with reduced liability to produce EPS and CNS side effects ${ }^{5}$. Olanzapine has high antagonist affinity to D1, D2, D3, D4 and 5HT 2A/2C. 
Olanzapine was superior than Ariprapazole, risperidone, ziprasidone where as there was no efficacy difference. amisulphride and clozapine were better than olanzapine in clinical efficacy ${ }^{6,7}$.

\section{Design \& Study Population}

This study is conducted in RIMS Psychiatry OP department from march 2016 to feb 2017. The study population included first episode schizophrenia male and female participant who have been diagnosed based on ICD-10 criteria. The therapeutic effects of olanzapine(5mg-30mg) and Lurasidone (40-120mg) were compared in these participants. The participants first episode schizophrenia patients 18-40 of subtypes Paranoid and Hebephrenic schizophrenia. They were administered PANSS scale ${ }^{7}$, CGI-S ${ }^{8}$, SAS scale during first evaluation, $6^{\text {th }}$ week and $12^{\text {th }}$ week of study. The Simpson Angus scale was administered on every visit of the patient.

\section{Inclusion Crtieria}

1) First episode schizophrenia either Hebephrenic or Paranoid subtype

2) Consent for interview

3) Consent to be linked to olanzapine or Lurasidone study group

4) Patients who can be managed on OP basis

\section{Exclusion Criteria}

1) Presence of any co-morbid psychiatry disorder

2) Use of any antipsychotics prior to study

3) Use of injectable depot antipsychotics prior to study

4) Pregnant, lactating women of child bearing who are not using adequate contraception.

5) Violent patients requiring injectable haloperidol or injectable benzodiazepine on high dose to control agitation.

Ethics committee approval: The study got approval from local ethics committee and was conducted according Good Clinical Practice guidelines by the Declaration of Helsinki

\section{Treatment}

Patients were allotted to olanzapine or Lurasidone group in alternate way i.e first diagnosed patient gets olanzapine and second diagnosed patient gets Lurasidone. The doses Olanzapine (10-20/day) and Lurasidone 40-120mg /day. The dose olanzapine was started $5 \mathrm{mg}$ and slowly titrated in the first week to $10 \mathrm{mg}$ and Lurasidone was titrated from $20 \mathrm{mg}$ to $40 \mathrm{mg}$ in the first week. For every raise of $5 \mathrm{mg}$ of olanzapine dose the dose of Lurasidone was raised by $40 \mathrm{mg}$. The maximum dose of olanzapine used in study was $20 \mathrm{mg}$ and Lurasidone $120 \mathrm{mg}$. Trihexyphenidyl was allowed to address extrapyramidal symptoms. Benzodiazepines were also allowed to alleviate anxiety and sleep symptoms while their usage was limited diazepam of dose not greater than $40 \mathrm{mg}$ which was down titrated by the end of $3^{\text {rd }}$ week

Assessment: Efficacy of treatment was measure change in baseline scores of PANSS and CGI-I to scores calculated at the end of study ( $12^{\text {th }}$ week).

The main goal of the study was to compare the efficacy of olanzapine and Lurasidone. A decline more than $50 \%$ of baseline score was considered improvement $^{10}$. The primary endpoint was analysed to intent to treat (ITT) patients (patients who completed at least on evaluation) and completer patients are patients who completed all evaluations. The patient who dropped in the middle of study their last observation was carried forward (LOCF)

\section{Statistical Analysis}

Comparing clinical efficacy of Lurasidone to that Olanzapine in treating first episode was goal of statistical analysis. PANSS score baseline, change of score and score at end point were primary variables of analysis. All patient who were examined at treated at least once (Intent to treat ITT) and patient who attended the entire study were analysed with Last observation carried forward for ITT population and entire scores for completer population. Patient safety was observed throughout the study 
The primary efficacy variable, the PANSS total score absolute change from baseline, was analysed according to null hypothesis and non-inferiority hypothesis; non-inferiority was considered confirmed if the 95\% 2-sided confidence interval calculated for the difference. Lurasidone minusolanzapine had an upper limit less than 8 points, corresponding to the non-inferiority margin defined in the protocol. a non-inferiority limit set at 8 points considered clinically relevant with regards to the placebo-active drug difference generally observed ${ }^{11}$. The variables age, height, weight and subtype of Schizophrenia were compared.

\section{Results}

Table 1 Demographic data:

\begin{tabular}{|l|c|c|c|c|c|}
\hline Demographic data & $\begin{array}{c}\text { Olanzapine } \\
\text { Mean(SD) }\end{array}$ & $\begin{array}{c}\text { Lurasidone Mean(SD) } \\
\text { Mean(SD) }\end{array}$ & Chi $^{2}$ & df & $\mathrm{p}$ \\
\hline Age $^{\text {a }}$ & $36(8)$ & $36(9)$ & 124 & 0.19 \\
\hline Height(a) & $160(12) \mathrm{cm}$ & $162(10) \mathrm{cm}$ & 124 & 0.30 \\
\hline Weight (a) & $70(10) \mathrm{kg}$ & $72(9) \mathrm{kg}$ & 124 & 0.23 \\
\hline \multicolumn{1}{|c|}{ SEX } & 37 & & & & 0.9 \\
\hline Male (b) & 23 & 26 & & 1 & 0.62 \\
\hline Female(b) & 46 & 54 & & & \\
\hline Paranoid (b) & 14 & 12 & & & \\
\hline Hebephrenic(b) & & & & & \\
\hline
\end{tabular}

The demographic data of the participants is given in table 1. The data has been evaluated using independent sample ' $t$ ' test and chi $^{2}$ test wherever applicable. The olanzapine and Lurasidone sample did not differ significantly with respect to demographic data

Table 2: Attrition and Non-improvement (PANNS reduction $<50 \%$ )

\begin{tabular}{|l|c|c|}
\hline Distrubiton & Olanzpine & Lurasidone \\
\hline Total (N) at entry & 60 & 66 \\
\hline Lost in $6^{\text {th }}$ week & 4 & 6 \\
\hline Lost in $12^{\text {th }}$ week & 5 & 8 \\
\hline Stopped treatment due side effects & 0 & 0 \\
\hline Total lost $6^{\text {th }}$ and $12^{\text {th }}$ week & 9 & 14 \\
\hline Total at end of study & 51 & 52 \\
\hline Attrition(a) & $15 \%$ & $21 \%$ \\
\hline .a -chi2 test.
\end{tabular}

Attrition rate did not differ significantly in Olanzapine and Lurasidone study group 
Table 3: PANSS, CGI-I, AND SAS

\begin{tabular}{|l|c|c|c|c|c|c|c|c|c|}
\hline Scale & \multicolumn{3}{|c|}{ Olanzapine } & \multicolumn{3}{|c|}{ Lurasidone } & & \\
\hline & $\begin{array}{c}\text { Baseline } \\
\text { Mean } \\
\text { (S.D) }\end{array}$ & $\begin{array}{c}\text { Endpoint } \\
\text { Mean }\end{array}$ & Change & $\begin{array}{c}\text { Baseline } \\
\text { Mean }\end{array}$ & $\begin{array}{c}\text { End point } \\
\text { Mean }\end{array}$ & change & F & p & $\begin{array}{c}\text { C.I } \\
\text { At } 95 \\
\%\end{array}$ \\
\hline PANSS & $\begin{array}{c}147.8 \\
(17.9)\end{array}$ & $\begin{array}{c}75.2 \\
(8.4)\end{array}$ & $\begin{array}{c}72.6 \\
(18.8)\end{array}$ & $\begin{array}{c}149.4 \\
(17.5)\end{array}$ & $\begin{array}{c}75.1 \\
(9.2)\end{array}$ & $\begin{array}{c}74.88 \\
(19.1)\end{array}$ & 0.65 & 0.513 & $-8.9+4.5$ \\
\hline CGI-I & 5.2 & 3.1 & 2.1 & $\begin{array}{c}5.3 \\
(1.2)\end{array}$ & $\begin{array}{c}2.8 \\
(1.1)\end{array}$ & $\begin{array}{c}2.5 \\
(1.2)\end{array}$ & 1.8 & 0.06 & $-.82+1.9$ \\
\hline SIMS & $\begin{array}{c}48.4 \\
(19.2)\end{array}$ & $\begin{array}{c}32.5 \\
(17.2)\end{array}$ & $\begin{array}{c}14.9 \\
(7.6)\end{array}$ & $\begin{array}{c}49.8 \\
(19.8)\end{array}$ & $\begin{array}{c}31.4 \\
(14.2)\end{array}$ & $\begin{array}{c}18.4 \\
(9.1)\end{array}$ & 1.6 & 0.09 & $-5.4+.47$ \\
\hline
\end{tabular}

Independent ' $t$ ' test was done in all three measurements PANSS, CGI-I and SAS scale. Olanzapine and Lurasidone group did not differ significantly.

\section{Results}

The participants in both groups were matched in age, height, weight and sex. The Schizophrenia subtype in both group did not differ significantly all the majority subtype is Paranoid Schizophrenia. The drop out in the Olanzapine group $15 \%$ and Lurasidone groups $21 \%$ which did not differ significantly. Efficacy measured through change in PANSS score and CGI-I group was around $50 \%$ in both groups and when compared on independent ' $t$ ' test and found the change of scores was similar in both groups ( $>>0.05$ at $95 \%$ $\mathrm{CI}$ ). The side effects were measured on Simpson Angus scale the initial ratings, baseline ratings and change in score from baseline to endpoint did not differ statistically in a significant way $(\mathrm{p}>0.05$ and CI of $95 \%$ ).

\section{Efficacy}

The study wanted to compare the efficacy of newly introduced Lurasidone in Indian population with already existing standard drug olanzapine. The attrition rate in the study ranged from $15-21 \%$ which is well below the accepted norm of $20 \%{ }^{15}$ PANSS which measures positive, negative and global psychopathology and CGI-I were used to measure the change and significance. Both groups showed decrease in symptoms severity in PANSS by $50 \%$.

These $50 \%$ decrease in symptom severity in both groups indicate both drug are effective in reducing the symptoms severity in Schizophrenia. The change in PANSS score was compared using independent ' $t$ ' test and the both groups did not differ significantly in quantitative improvement in both group suggesting Lurasidone is as effective as Olanzapine. The mean dose of Lurasidone was $80 \mathrm{mg} /$ day and that Olanzapine was $10 \mathrm{mg} /$ day. After disproving the null hypothesis, the noninferiority as described in protocol was done. Its found that Lurasidone is non inferior to Olanzapine in reducing the symptoms ${ }^{15,16,17}$

CGI-I score also indicated both drugs caused marked improvement in reducing the severity of illness.

The Simpson Angus score which measures the motor side effects of antipsychotics has been similar in both groups did not show increase the score at end point of study. The neuromuscular side effects by both drugs were similar intensity in both groups.

\section{Conclusion}

Lurasidone is as efficacious as Olanzapine in treatment of first episode Schizophrenia. Side effect profile of Lurasidone was similar to Olanzapine 


\section{Limitations of the study}

1) Open label study result do not form a good qualitative evidence.

2) Hospital based study cannot generalized natural population.

3) Shorter duration of study would have resulted initial larger gains in improvement.

4) Sample size small to extrapolate the results of study

5) Another scale along with PANSS should have been used like BPRS.

6) Quality of life measurements should also have been made.

\section{References}

1. Häfner H, an der Heiden W. Epidemiology of Schizophrenia. The Canadian Journal of Psychiatry. 1997;42:139-151. doi:10.1177/070674379704200204

2. Messias, Erick, Chuan-Yu Chen, and William W Eaton. "Epidemiology of Schizophrenia: Review of Findings and Myths." The Psychiatric Clinics of North America 30, no. 3 (September 2007): 32338.

https://doi.org/10.1016/j.psc.2007.04.007.

3. Jablensky, A., N. Sartorius, G. Ernberg, M. Anker, A. Korten, J. E. Cooper, R. Day, and A. Bertelsen. "Schizophrenia: Manifestations, Incidence and Course in Different Cultures. A World Health Organization Ten-Country Study." Psychological Medicine. Monograph Supplement 20 (1992): 1-97.

4. Kumar, Ajit, Soumitra S. Datta, Stephen D. Wright, Vivek A. Furtado, and Paul S. Russell. "Atypical Antipsychotics for Psychosis in Adolescents." The Cochrane Database of Systematic Reviews, no. 10 (October 15, 2013): CD009582. https://doi.org/10.1002/14651858.CD0095 82.pub2.

5. Ishibashi, Tadashi, Tomoko Horisawa, Kumiko Tokuda, Takeo Ishiyama, Masaaki
Ogasa, Rie Tagashira, Kenji Matsumoto, et al. "Pharmacological Profile of Lurasidone, a Novel Antipsychotic Agent with Potent 5-Hydroxytryptamine 7 (5$\mathrm{HT}_{7}$ ) and 5-HT $\mathrm{HA}_{1 \mathrm{~A}}$ Receptor Activity." Journal of Pharmacology and Experimental Therapeutics 334, no. 1 (July 1, 2010): 171. https://doi.org/10.1124/jpet.110.167346

6. Rummel-Kluge, Christine, Katja Komossa, Sandra Schwarz, Heike Hunger, Franziska Schmid, Werner Kissling, John M Davis, and Stefan Leucht. "Second-Generation Antipsychotic Drugs and Extrapyramidal Side Effects: A Systematic Review and Meta-Analysis of Head-to-Head Comparisons." Schizophrenia Bulletin 38, no. 1 (January 2012): 167-77. https://doi.org/10.1093/schbul/sbq042.

7. Komossa K, Rummel-Kluge C, Hunger H, Schmid F, Schwarz S, Duggan L, Kissling W, Leucht S. Olanzapine versus other atypical antipsychotics for schizophrenia. Cochrane Database Syst Rev. 2010 Mar 17;(3):CD006654. doi: 10.1002/14651858.CD006654.pub2.

Review. PubMed PMID: 20238348; PubMed Central PMCID: PMC4169107.

8. Bell M, Milstein R, Beam-Goulet J, Lysaker P, Cicchetti D. (1992): The Positive and Negative Syndrome Scale and the Brief Psychiatric Rating Scale. Reliability, comparability, and predictive validity. J Nerv Ment Dis180: 723-728

9. National Institute of Mental Health. (1976a): Clinical Global Impression. In Guy W (ed), ECDEU Assessment Manual for Psychopharmacology Revised Edition. Rockville, MD, National Institute of Mental Health, pp 218-222

10. Simpson G, Angus JA. (1970): A rating scale for extrapyramidal side effects. Acta Psychiat Scand45(Suppl 212):11-19

11. Leucht, Stefan, John M. Kane, Werner Kissling, Johannes Hamann, Eva Etschel, 
and Rolf R. Engel. "What Does the PANSS Mean?" Schizophrenia Research 79, no. 2-3 (November 15, 2005): 231-38. https://doi.org/10.1016/j.schres.2005.04.00 8.

12. Beasley CM, Sanger T, Satterlee W, Tollefson G, Tran P, Hamilton S, the Olanzapine HGAP Study Group. (1996a): Olanzapine versus placebo: results of a double-blind, fixed-dose olanzapine trial. Psychopharmacology124: 159-167

13. Citrome L. Lurasidone for schizophrenia: a review of the efficacy and safety profile for this newly approved second-generation antipsychotic. Int J Clin Pract. 2011 Feb;65(2):189-210. doi: 10.1111/j.17421241.2010.02587.x. Epub 2010 Dec 3. Review. PubMed PMID: 21129135.

14. Amico, K Rivet. "Percent Total Attrition: A Poor Metric for Study Rigor in Hosted Intervention Designs." American Journal of Public Health 99, no. 9 (September 2009): 1567-75. https:// doi.org/10.2105/AJPH.2008.134767.

15. Nakamura, Mitsutaka, Masaaki Ogasa, John Guarino, Debra Phillips, Joseph Severs, Josephine Cucchiaro, and Antony Loebel. "Lurasidone in the Treatment of Acute Schizophrenia: A Double-Blind, Placebo-Controlled Trial." The Journal of Clinical Psychiatry 70, no. 6 (June 2009): 829-36. https://doi.org/10.4088/JCP.08m04905.

16. Risbood, Vineeta, Jennifer R. Lee, Jennifer Roche-Desilets, and Matthew A. Fuller. "Lurasidone: An Atypical Antipsychotic for Schizophrenia." The Annals of Pharmacotherapy 46, no. 7-8 (August 2012): 1033-46. https://doi.org/10.1345/aph.1M721.

17. Goldman, Robert, Antony Loebel, Josephine Cucchiaro, Ling Deng, and
Robert L. Findling. "Efficacy and Safety of Lurasidone in Adolescents with Schizophrenia: A 6-Week, Randomized Placebo-Controlled Study." Journal of Child and Adolescent Psychopharmacology 27, no. 6 (August 2017): 516-25. https://doi.org/10.1089/cap.2016.0189. 